\title{
Dog-bite lacerations: a controlled trial of primary wound closure
}

\author{
C. MAIMARIS \& D. N. QUINTON
}

Accident and Emergency Department, The Leicester Royal Infirmary, Leicester, England

\section{SUMMARY}

Dog-bite wounds are often left open because of their reputation for infection if 9 primarily closed.

A prospective randomized trial comparing primary closure with leaving the wound $\mathbb{\Phi}$ open was performed to assess infection and cosmesis. Ninety-six patients with $169 \stackrel{\frac{0}{D}}{\circ}$ lacerations had thorough surgical debridement and irrigation of their wounds. Ninety- $\bar{Z}$ two wounds were sutured and 77 left open. No prophylactic antibiotics were given. A $\stackrel{\mathbb{\Phi}}{-}$ total of 13 wounds developed infection: seven sutured and six unsutured wounds (nळ $\vec{\circ}$ statistically significant), giving an overall infection rate of $7 \cdot 7 \%$. Significant $(P<0.01)$, more wound infections occurred in the hand in both groups compared to the rest of the body, indicating that particular attention should be paid to management of such wounds.

It was concluded that dog-bite wounds should receive thorough surgical treatment and can be safely sutured at presentation. Special care should be given to hand wounds.

\section{INTRODUCTION}

Dog bites are a common problem presenting to the accidental and emergency (A\&E) department. These represent $1-2 \%$ of new attendances (McKee \& Bryce, 1983).

Forty per cent of all dog bites present with a laceration. Primary management is directed towards prevention of sepsis and rapid wound healing, with good cosmesis.

Several studies have documented the problem of wound infections (Callaham, 1978; $\frac{}{0}$ Callaham, 1980b), the causative organisms (Aghababian, 1980) and the use of prophylactic antibiotics (Callaham, 1980a). Less emphasis has been given to the surgical $\stackrel{\circ}{\circ}$ treatment of these wounds: wound exploration, toilet, debridement and trimming of $N$ devitalized skin edges, irrigation, and wound closure (Snook, 1982).

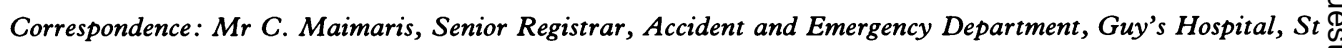
Thomas Street, London SE1 9RT, England 
In the past, there has been considerable controversy regarding the suturing of dog bite wounds (Evans et al., 1982). In recent years, primary closure of facial wounds is considered acceptable in plastic surgery units (Palmar \& Rees, 1983).

The present authors decided to perform a prospective randomized trial of dog bite lacerations, to assess the role of primary wound closure in A\&E.

\section{PATIENTS AND METHODS}

Patients of all ages attending the A\&E department with a dog bite were selected for a prospective, randomized trial. Those wounds requiring surgical treatment (more than $3 \mathrm{~mm}$ ) were entered into the trial. Puncture wounds (less than $3 \mathrm{~mm}$ diameter), infected wounds at presentation, wounds with skin loss requiring plastic surgery, or wounds where other structures were involved (e.g. nerve, tendon, joint or bone), were excluded from the trial.

Notes were taken of the delay between the dog bite and treatment, and the number, site and size of wounds. All patients were up-dated for tetanus immunization.

The lacerations were cleaned with a solution of cetrimide $0.5 \%$ and chlorhexidine $0.05 \%$. Debridement of wound and skin edges was undertaken where necessary under local anaesthetic. Irrigation of the wound was then performed with $50 \mathrm{ml}$ of normal saline using a $20-\mathrm{ml}$ syringe and $19-\mathrm{g}$ needle. The bleeding was stopped and the wound was dried with a swab. The patients were then randomized into two groups: one group had primary wound closure. The suture material was 4/0 Ethilon for most lacerations and $6 / 0$ Ethilon to the face. In the second group, the wounds were left open. At the run up to the trial the use of one or two steri-strips was allowed in large lacerations, but it was found that a seroma often collected under the steri-strips which might encourage infection. The use of steri-strips was, therefore, abandoned.

All wounds received a Jellonet dressing with gauze and crêpe bandage. A high sling was used in the upper limb and elevation was advised for the leg. No antibiotics were used. The management of simple lacerations was undertaken by experienced nursing staff in the A\&E department. In complicated wounds, especially in the hand, the patient was treated in the operating theatre by an experienced member of the medical staff.

Patients were reviewed by one of the authors at $48 \mathrm{~h}$ and 7 and 14 days from the injury. Wounds were examined for infection (serous exudate, inflammation without pus, infection with systemic effects). Infected wounds had wound swabs taken which were cultured both in anaerobic and aerobic conditions. Infected wounds were then explored in theatre and under appropriate anaesthesia. The wounds were cleaned and irrigated and antibiotics commenced. The antibiotics were given according to the sensitivity of the organisms grown from the wound swabs. The patient's review was continued until the wound had healed.

Wounds were classified at each review as completely or partly healed, or gaping. Wound cosmesis was classified into good, fair and poor results. The maximum width of the wound scar was measured in millimetres. Statistical analysis was carried out comparing the two groups. The Chi square test, with Yates correction where necessary, was used. 


\section{RESULTS}

Between September 1987 and January 1988, 96 patients entered the trial with 169? wounds: 57 were male and 39 female. The age range was $2-83$ years old with $60 \%$ of the $\overrightarrow{\vec{s}}$ patients being less then 30 years of age.

After randomization, 92 wounds were sutured and 77 were left open. The distribu-흠 tion of these wounds according to the site in each group is shown in Fig. 1. It is $\frac{\bar{\rho}}{\bar{\rho}}$ noticeable that $44 \%$ of these wounds were in the hands.

The length of the wounds were measured in millimetres and the distribution is shownis in Fig. 2. It can be seen that $55 \%$ of the lacerations were one centimetre or less.

Thirteen wounds developed infection during the course of the trial giving an overall $\vec{\omega}$ infection rate of $7 \cdot 7 \%$. The distribution of these infections according to site and group ${ }^{\omega}$ is shown in Fig. 3. Notably, nine wound infections occurred in the hands. Of the 133 infected wounds, seven developed frank pyogenic infection, five of which were causedir by Staph aureus and two by Pastuerella multisoda and B-Haemolytic streptococcus. Six $\dot{\omega}_{\vec{H}}$ wounds had cellulitis of which one had Moraxella and the remaining no growth.

Statistical analysis was carried out comparing the results in the two groups. There was no significant difference of infection between the groups when compared with ${ }_{\infty}^{-}$ respect to age, sex, site of the wound, or whether the wounds were primarily sutured ord left open. However, significantly more wound infections occurred to the rest of the bodyळ $(P=0 \cdot 01)$.

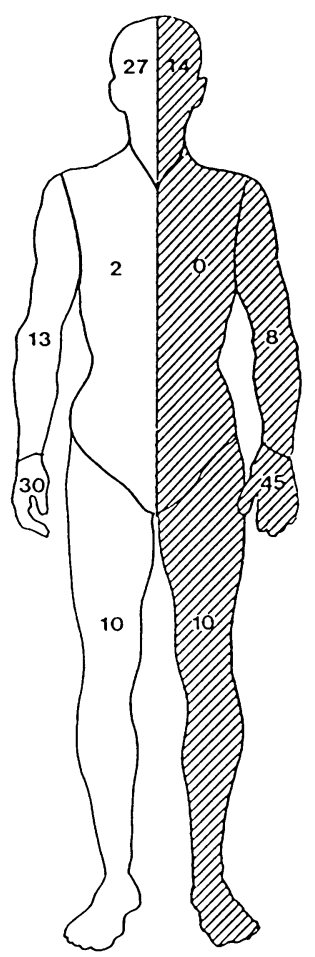

Fig. 1. Distribution of wounds according to site ( $\square$ sutured wounds; $\mathbb{E}$ unsutured wounds). 


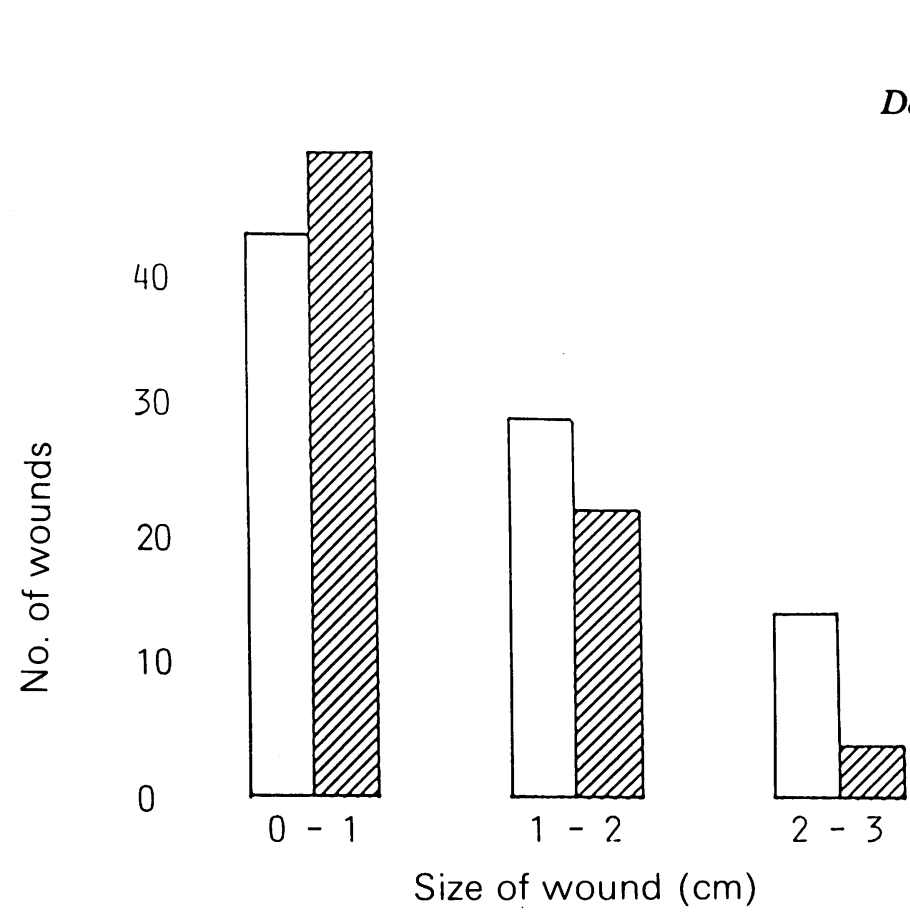

Dog-bite lacerations

159

Fig. 2. Wound size (cm).
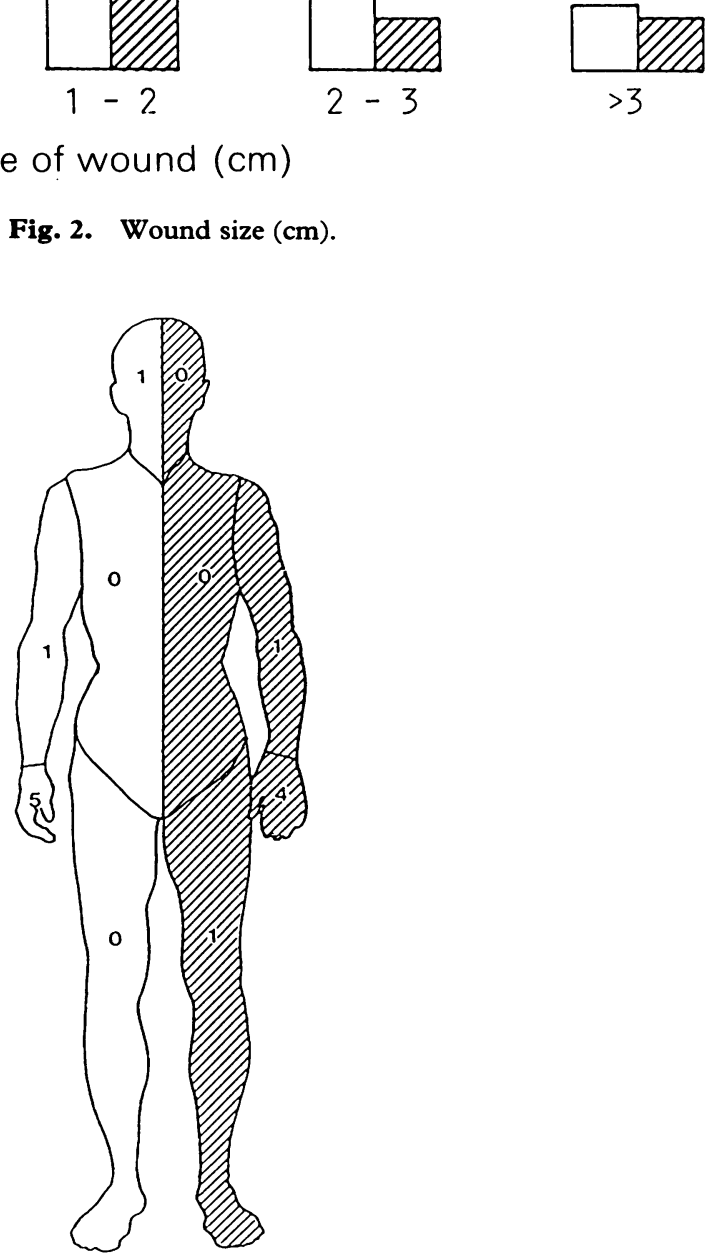

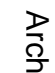

$\frac{\mathrm{m}}{3}$

ㅇํㅇ

$\stackrel{\vec{B}}{\stackrel{B}{9}}$

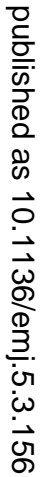

운

c)

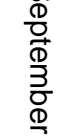

$8 \overrightarrow{0}$

웅

훟ㅁำ

ํํำ

(1)

윽

F

(1)

$\frac{10}{3}$

옹

잉

을.

N

谂

ছ

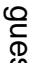

Fig. 3. Distribution of infected wounds. 
The average delay of presentation was $2.5 \mathrm{~h}$ (range $30 \mathrm{~min}$ to $24 \mathrm{~h}$ ). Delay of presentation of more than $10 \mathrm{~h}$ was noticed to be associated with an increased infection rate. Similar delays were also noted in four patients who were not included in the triaf. because they presented with established infections.

Wound healing was satisfactory in both groups. Wound cosmesis was considered toog be good or fair in all patients, with mean scar width of $3 \mathrm{~mm}$ in unsutured $(2-6 \mathrm{~mm})$ ande $1.9 \mathrm{~mm}$ in sutured wounds $(1-5 \mathrm{~mm})$.

\section{DISCUSSION}

Leaving open dog-bite lacerations even with secondary closure, is unsatisfactory to both the doctor and the patient alike. Although closure of the facial wounds is safe in thei absence of antibiotics (Palmar \& Rees, 1983), it was felt that, after thorough surgicakg management, primary closure of dog bite lacerations over the rest of the body should beo performed.

There were two problems at the start of the trial. These exemplify the difficulties of treating such wounds. When one or two steri-strips were used to approximate the edges $\frac{\mathbb{0}}{\mathbb{0}}$ of larger wounds these quite rapidly developed a seroma under the steri-strips and showed signs of infection. This practice was, therefore, abandoned.

The smaller wounds which were left unsutured initially had a higher incidence $\$ f_{\circ}$ infection. This was found to be due to poor cleansing, the attendant hoping that leavingo the wound open might prevent infection. This is in agreement with one stự̂응 (Callaham, 1980b) which found that $10 \%$ of sutured wounds became infected compareds with $21 \%$ of those left open.

In this study, the infection rate of sutured wounds was $6 \cdot 6 \%$. This comparesूँ favourably with previous papers which have shown an overall infection rate of $6 \%$ to 13\% (Callaham, 1978; Aghababian, 1980).

Suturing hand wounds appears to be associated with an increased infection rate Rigorous treatment of these wounds with careful cleaning and irrigation should be undertaken in a fully equipped operating theatre by experienced medical staff.

The delay of presentation and treatment of dog bite lacerations was shown in this: study to have an increased risk of infection. This is again in agreement with previous? papers (Callaham, 1978). The present authors would not advocate closure of these wounds.

The size of the wound appears unimportant especially when one considers the high음 incidence of infection in puncture wounds (Callaham, 1978). This is rather surprising as? one would have thought the larger wounds would have been easier to debride and irrigate.

This study clearly shows that after surgical treatment of dog bite lacerations the 0 primary closure makes no difference to the infection rate (except in hand wounds) and the cosmetic result is good and more acceptable to the patient than leaving the wound open.

Our patients were followed up for the purposes of the trial. Normally after primaryọ suture patients are able to be discharged to the care of their general practitioners. This 
compares with outpatient visits for supervision and secondary closure of wounds left open. This, in the face of increasing demands on A\&E services, makes a saving on medical and nursing staff time.

Dog-bite lacerations should receive thorough surgical treatment and can safely be sutured at presentation. However, special care should be given to hand wounds and patients with delayed presentation.

\section{ACKNOWLEDGEMENTS}

We thank the staff of the A\&E Department, The Leicester Royal Infirmary for their help with this trial and Robert Hutton for secretarial help.

\section{REFERENCES}

Aghababian R. V. \& Conte J. E. (1980) Mammalian bite wounds. Annals of Emergency Medicine 9, $79-83$.

Callaham M. (1978) Treatment of common dog bites: infection risk factors. Fournal of the American College of Emergency Physicians 7, 83-7.

Callaham M. (1980a) Prophylactic antibiotics in common dog bite wounds: a controlled study. Annals of Emergency Medicine 9, 410-14.

Callaham M. (1980b) Dog bite wounds. Fournal of the American Medical Association 244, $2327-8$.

Evans D., Iqbal J. \& Maitta A. (1982) Dog bites in man. British Medical fournal 248, 742-3.

McKee R. \& Bryce G. (1983) Animal and human bites as an emergency. Health Bulletin 41, (3) $137-40$.

Palmer J. \& Rees M. (1983) Dog bites of the face. A 15-year review. British fournal of Plastic Surgery 36, 31518.

Snook R. (1982) Dog bites in man. British Medical fournal 248, 293-4. 